\title{
Evolución y crítica de un problema social. Conversos y oposición inquisitorial: el caso del memorial anónimo de 1538
}

\author{
Rica AMRAN *
}

\begin{abstract}
RESUMEN
ABSTRACT

En el presente trabajo presentamos una crítica a la actuación del Santo The present work it is a critical study about the performance of the Santo Oficio in the times of Charles I. The unkown author of the Memorial explains the causes that led to the restoration of the New Inquisition in the years of the Catholic Kings (Reyes Católicos). The motives of the renovation were complete different from those of the following century (xvith) hence his writting of the Memorial.
\end{abstract}

\section{INTRODUCCIÓN}

En la historia de la minoría judía en tierras peninsulares, el año 1391 marca el inicio de un periodo de grandes conversiones que terminarán sólo en 1492. Las persecuciones iniciadas en Toledo a finales del siglo XIV, y que se expandieron por toda la Península Ibérica, llevaron a muchos judíos a convertirse al cristianismo, un fenómeno conocido en siglos ante-

\footnotetext{
* Universidad de Lille III.
} 
riores. Sin embargo los casos de conversión realizados anteriormente al año 1391 habían sido aislados, generalmente estos estuvieron totalmente convencidos de la verdad de la fe a la cual se adhirieron. $Y$ he aquí el cambio: las conversiones realizadas en el periodo al que hacemos alusión fueron en su mayoria forzadas por el miedo ${ }^{1}$.

Una vez pasado el peligro, algunos de estos «nuevos cristianos» desearon volver a su religión de origen, pero habían pasado ya a depender de la jurisdicción eclesiástica, que se encargaría a partir de estos momentos de supervisarlos y adoctrinarlos.

Ante este hecho consumado, una parte, en estos años de finales del siglo XIV, se vieron «obligados» a huir hacia el norte de Africa. En contraposición, un gran número decidió quedarse, algunos creyendo poder llevar una «doble vida», otros convencidos de la elección religiosa que habian realizado?

Un hecho constatamos: a partir de 1391 los conversos nos son individuos aislados sino una multitud que va a hecer «temblar» los pilares de la sociedad medieval peninsular, y que originarán la aparición de un nuevo fenómeno social ${ }^{3}$.

Ellos se adaptaron pronto a su nueva situación y posición, Muchas «puertas» que les estaban vedadas como judíos se les abrieron súbitamente. Podían participar a todos los niveles en la vida política, social (in-

«...avia robado la Juderia, é que eran tornados christianos los mas Judios que y eran, é muchos de ellos muertos. E que luego que estas nuevas sopieron en Cordoba, é en Toledo, ficieron eso mesmo, y asi en otros muchos logares del Regno.E sabido por el Rey como los Judios de Sevilla é de Cordoba é de Toledo eran destroidos, como quier que enviaba sus cartas é ballesteros é otros logares por defender, en tal manera era el fecho encendido, que non cedieron ninguna cosa por ello.E todo esto fué cobdicia de robar, segund paresció, mas que devocion...". Crónica de Enrique III, ed. de Cayetano Rosell, BAE, 68 (1953), p. 177. AMRÁN, R., «Judíos y conversos en las crónicas de los Reyes de Castilla (desde finales del siglo xIv hasta la expulsión)", Espacio, Tiempo y Forma, 9(1996), p. 259.

a AmRÁN, R., «La situación de los judíos en el norte de Africa según el libro de los Veedores de Ceuta" y "The Present State of the Jews in the North Africa», in Hommage à H.V. Sephiha, dirigé par Winfried Busse et Marie Christine Varol-Bornes, Berlin, 1996, ed. Peter lang, coll. Sephardica, pp. 435-343. AMRÁN, R., «Juifs et musulmanas à Ceuta aux xviè et xvilè siècles», in Relations judèo-musuimanes au Maroc, perceptions et réalités (ouvreage collectił dirigé par Michel Abitbol), Paris, 1997, pp. 79-88. AmRán, R., «El caso del aprovisionador Fernando de Montesinos Téllez, aprovisionador de la plaza de Ceuta", Instituto de Estudios Ceuties, Homenaje al Profesor Carlos Posac Mon, II (1998), pp. 81-91.

3 Bentto Ruano, E., De la alteridad de la Historia (discurso leído en la Real Academia de la Historia), Madrid, 1988, pp. 81-94. CARO BAROJA, J., Los judios en la España moderna y contemporánea, Madrid, 1986, vol I, pp. 125-147. MonSALVO ANTÓN, J.M., Teoría y evolución de un conflicto social. El antisemitismo en la Corona de Castilla en la Baja Edad Media, Madrid, 1985. VALDEÓN BARUQUE, J., Los conflictos sociales en el reino de Castilla en los siglos XIV Y XV, Madrid, 1983. 
cluida en las jerarquías eclesiásticas) y económica del reino, y además podían continuar detentando aquellos puestos que antes como judíos había realizado.

La nueva situación provocará un cambio fundamental en la mentalidad, y las revueltas toledanas de 1449, con la promulgación del primer estatuto de «limpieza de sangre» son un claro testimonio de los ánimos exaltados que corrían por aquellos tiempos en el ámbito peninsular.

En la crónica de Enrique IV se nos hable de la situación:

«...pero más, después que el terrible despojo de los conversos acusados de apostasía, provocó los tumultos de Toledo. Este dió causa a que, so pretexto de extipular las supersticiones introducidas por aquellos, excitados los ánimos de los plebeyos, se lanzasen al saqueo con tal furor, que temerosos luego de los crímenes perpetrados tuvieron que acogerse al amparo de D. Pedro Sarmiento, caballero de noble alcurnia, pero de depravadas costumbres, rebelándose osadamente contra la autoridad del Soberano...” ${ }^{4}$.

Y también vemos que como única y legítima solución posible se nos da la creación de la nueva Inquisición, que debía verificar sistemáticamente que aquellos nuevos conversos fueran verdaderos creyentes ${ }^{5}$. Es así como la expulsión de los judíos tuvo como meta aislar a aquellos que dudaban (de forma pública o secreta) de su nueva fé, para que no pudieran volverse hacia sus antiguos correligionarios.

De esta forma, a finales del siglo $\mathrm{xv}$, nos encontramos con una situación en la cual todo cristiano nuevo es sospechoso de ser un «mal cristiano", hasta que no pruebe lo contrario.

En este clima evidente de tensiones, la polémica se agudiza, tendencias «pro y anti» conversas dan pie a ríos de tinta, es decir a la publicación de opósculos y libros, algunos anónimos, redactados por hombres de Iglesia, sobre todo, y seglares, preocupados por aclarar y explicar, sus puntos de vista sobre el tema.

Veremos como la Inquisición clasificará como peligroso este «fervor»literario, e intentará establecer un «control cultural», sumiendo la impresión de obras a una actividad dependiente del Santo Oficio ${ }^{6}$. A partir de finales del siglo Xv los autores se verán obligados a obtener licencias de impre-

\footnotetext{
4 Crónica de Enrique IV, ed. de Paz y Meliá, BAE, I (1973), p. 12. AmRÁN, R., Judíos y conversos, pp. 262-263.

5 Crónica de los Reyes Católicos, ed. de Cayetano Rosell, BAE, 70 (1953), pp. 331-332. AmRán, R., Judíos y conversos, p. 267.

6 Pinto Crespo, V., Inqusición y control ideológico en la España del siglo xvi, Madrid, 1983.
} 
sión, las imprentas serán vigiladas, permitiéndose los inquisidores el poder llegar a prohibir distintos trabajos según su tendencia, las ideas exprimidas, «herejías» y probables "conspiraciones», provocando como consecuencia un control sobre la importación de libros: las nuevas ideas y tendencias traspasaran cada vez menos los Pirineos.

La activiciad de los censores se desarrolló y se perfeccionó, las listas de «libros prohibidos» se sucederán y se ampliarán a partir de mediados del siglo $\mathrm{XVI}{ }^{7}$.

\section{EL TEXTO}

En este clima de tensiones y cambios de principios del siglo xvI surge el Memorial anónimo de 1538, que se inicia con una descripción de dónde y cuándo fue hallado el texto y de las particularidades del mismo ${ }^{8}$ :

«En la ciudad de Toledo a nueve días del mes de mill y quinientos / y trenta y ocho años estando en consejo de la santa Inquisicion los se / ñores del dicho conssejo el obispo de Badajoz, traxo un enboltorio de cartas / questava ybtitulado en el covertor del encitamanera = alos muy magnificos / Señores dean y cavildo de la sancta Iglesia de Toledo de Porse tres Reales / digo tres Reales y dentro del dicho en voltorio vernian tres cartas Launa / enderecadaal emperador y rey nuestro escrita en tres oxas de medio Pliego / de Papel y Parte dela quartar hoxa la mitad de la primera plana / della. Y La otra a los de su consejo Real enmedio Pliego de Papel escrita / casi toda La una Plana della $=$ y La otra al Dean y cavildo de la Santa Iglesia / De Toledo asimismo escrita en una Plana,el qual icho enboltorio / Dixo el dicho señor obispo que se lo avia dado abierto el llustrísimo y Reverendísimo Cardenal / de Toledo ...pues en las dichas cartas se trataba y ablava / en cossas tocantes al sancto officio las quales dichas cartas y cobertos/son las que síguen/ ... ${ }^{9,10}$.

El opósculo va dirigido a Carlos I de España, y comienza con la explicación del por qué del mismo, de la meta de este: la reforma de la

Caro Broja, J., Las formas complejas de vida religiosa, Madrid, 1995, vol. I, pp. 329-335.

El Memorial anónimo de 1538, AHN, Irquisición, Lib. 1325, fols. 23-20.

9 Imprescindible para este trabajo ha sido el artículo del Prof. Avilés, ya que en la segunda parte del mismo nos habla del Memorial. Avilés Fernández, M.A., «Motivos de crítica a la Inquisición en tiempos de Carlos $\mathrm{V}$ (aportaciones para una historia de la oposición a la Inquisición)", La Inquisición Española, nueva visión, nuevos horizontes, Madrid, 1980, pp. 184-192. Ver también: Caro Baroja, J., Los judíos, II, pp. 185-456. Netanyahu, B., Los orígenes de la Inquisición, Barcelona, 1999, pp. 839-984.

10 He intentado respetar lo más posible la ortografía empleada por el autor, aunque he separado las palabras que normalmente el escribió unidas. En el manuscrito que hemos consultado, hemos llegado a observar un promedio de tres palabras unidas, y un máximo de seis. 
Inquisición para hacerla más justa, ya que, en su opinión se estaba castigando a inocentes.

«Buen Rey Baron Çima de la casa de Austria / Segun siento en lo ynterior siendo con tinta y papel, sino cn lagrimas / de sangre quisiera delante Su acatamiento descubrir mi coraçon / y de los mas que vivimos en esta Su preciada Hespaña Para que como / supremo dépues de dios des el Remedio convenible a la buena governa / cion de Sus Reynos el qual Jesucristo se inspire/.

Buen Rey no se escandalices Porque pedirte Reformes la santa Inqusición / oye como catholico que antes es aumento que no disminucion, claridad / que no tinieblas lo que nuestra Parte se pide Para gloria de Dios aumento / de nuestra santa Fee Su Magestad Ympedido en el exercicio militar y los cava /lleros por seguirte y los Prelados de la yglesia de Dolersse Poco de sus/ feligreses y los ydalgos porque no digan que les toca y les escudriñan / los linajes hasta Adan, y los conversos de miedo y los labradores / por bengarse de los conversos no te piden ni saben ni osan Pedir remedío / no para quitar la santa Inquisicion que no seria cristiano quien tal / pidiesse sino Para aumentarla y aclararla,no desmenbrarla Reformarla / con la lunbre y gracia del espiritu sancto que ynfluia en sus ynteriores / entrañas y de los Catholicos grandes Prelados y de los del tribunal y alto/ consejo para que rreconociendo la mejoria que por la gracia de dios, ay en sus sub/ditos españoles y como por la gracia de dios se puede Intitular España / Christianissima como es notorio ansi se encomienda el rrigor del castigo / con la mudança de obras porque no se de lugar que por castiga algun culpado / padezcan muchos ynocentes y seria mexor segun su rreal justicia y segun / ley de christo que se dexen de castigar algunos culpados Porque no padezcan / los ynocentes. $Y$ es dios testigo que si su rreal magestad no pone rremedio / en reformacion en ello que a avido y ay muy orandissimo Aparexo $Y$ aun / por mexor decir ques ympossible no padecer muchos Ynocentes pluguiose a / Dios que lo pudiese y orasse decir como lo siento que pordriaser que para lo / subcedido y que cada dia esta en la mano de suceder no me bastassen mill / pliégos de escritura..." ${ }^{11}$.

En opinión del autor del opúculo cuando la Inquisición se estableció la sociedad hispana se encontraba muy mezclada, y las relaciones entre musulmanes, cristianos y judíos eran muy estrechas, por lo que la instauración del Santo Oficio estuvo justificada. Pero desde el momento que se produjo la expulsión de las minorías, el papel del tribunal dejó de ser claro, y de ahí la necesidad de reformarlo. Aduce que de haber estado aun en vida los Reyes Católicos, estos hubieran realizado su transformación:

«Buen Rey quando Los Reyes de glosirssa memoria ynstituyeron / el rigor del sancto oficio fue muy nesçessario porquestavan muy mez/ cladas

11 Fol. 13v. 
teres leyes Moros, e judios, e christianos y los unos convertian / a los otros y los otros a los otros, y colapadamente tenían aparexo / de lugar con las leyes a estira a floxa y en la mañana era uno christiano / y a medio dia Moro y a la noche Judio y Vista la total perdicion / convino echar los moros e judios des Espana e derribar las sinogas emez /clitas y ynstituir con todo en el rigor del mundo la sancta Inquisicion / e convino e fue necesario con todo el favor del mundo ... de a que esas malas sectas y excrutandlo en algunos escarmentaban otros / asta que por la bondad de Dios se rreformado nuestra España y vemos / que mejores exemplos y obras e memorias hacen los conversos en / la onrra de dios que otras gentes Porque el espiritu santo provee a la mayor / necesidad y en esto se manifiesta mas la grandeca de Dios y asi buen rrey acavo de / cinquenta años que fue el destierro todos los que ssavian algo en tal ley de moros y / judios son muertos y si vivieron algunos son chiquitos y a la sacon lo que bian no enten / dian y despues a ca no a avido a Parexo para prender pue smudandose los tiempos / e mudandose las obras y rreformandos las gentes en buen bivir y quitandose los / a Parexos del mal vivir justo ser rreforma el rreyno como no se agan mirasen por / culpados los ynocentes Por reberencia de Dios lo mirad, y pone el sentido en ello / que se tratan como herejes con toda la crueldad del mundo las gentes antes que / se averigue sello o no cosa es no vista y a mas y de mayor dolos y si los Reyes catho/ licos fueron Vivos veinte años za que lo obieran rreformado vista la mudanca / de las obras y como muchos sin causa pueden ser afrontados en este sancto / oficio por el rrigor de sus ordenanças y la poca verdad que ay en la gente Para atestiguar...»12.

Continua justificando su postura y explicándonos no creer en la utilidad de la Inquisición, añadiendo que incluso los libros redactados en árabe y hebreo hacía cincuenta años que habían sido quemados. Por lo que en realidad se estaban realizando falsas acusaciones a hombres buenos, e incluso algunos de los pecados de los que se acusaba a los inculpados no concernían al Santo Oficio:está poniendo en duda los juicios de los inquisidores.

«Buen Rey de que sirve a nuestra sancta fee catholica que se trayga la ley / de moysen y de Maoma escrita de molde en una carta de hedito quetrayn / los ynquisidores de que sirve predicarlas por los pulpitos pues que a cinquenta / años questan quemados todos los libros hebraycos y aravigos, y los que / los savian leer y entenden son muertos figuraseme que no para mas sino para / que si algun mal christiano ay en lo ynterior acierte amexor hacer su cere / monias y Para los que nos avian que cossa hera Judaicar o seguir la secta mahometana lo aprendan para quel diablo que eso me los engañe, o para que / los enemigos en enbidiosos tome bengança de sus enemigos y esto es de doler / ...

12 Fol. 14r. 
Evolución y crítica de un problema social. Conversos y oposición inquisitorial...

Buen rrey de sirbe que se prendan por la sancta Inquisicion / por lixeros yndicios y por cossas muy livianas y cosas que bastaría / un buen confessor para castigarlas o alo menos los jueces ordinarios...» ${ }^{13}$.

Nos describe el trato inhumano que se les daba a los detenidos, el restar años sin juicio hasta que se realizaban públicamente pomposos autos de fe, y de los efectos psicológicos que en ellos se producían cuando esperaban, totalmente aislados, en las cárceles inquisitoriales:

«Buen rrey el que sirve a la santa fee esperara que se hagan de tres a tres / aos y quatro a quatro unos autos muy poderosos autoricados como / quando van a canonicar aun sancto es por meritar para mientras se / junta una gran multitud de culpados se esten otros tristes pressos esperando / ...comiendosse sus haciendas en las tristes / carçeles y que carçeres, y para que sus hijos mugeres y deudos brisan / en perpetua misseria y tristeça hasta ber el fin y para que muchos hombres / y mugeres flacos y de poco animo, aun los de mucho biendo questan sus pleytos / conclussos tantos tienpos y años y no los sueltan piensan questan con de / nados para la quema y como los requieren cada dia se reconcilien / los mas por vivir y no esperar tanto tiempo la muerte la muerte / creyendo que los ande quemar se rrinden y destruyen asi y a todos quan / tos se les antoxa por vivir porque quien sera tan fuerte y constante que / pueda estar entre quatro paredes solo sin que levea persona terrenal con temor / y sospecha que cada dia que oye rruido en la carcel es para sacarle a quemar / que un dia o dos puede durar al hombre el animo y corage y aun a una muger / delicada para esperar la muerte y decir y proponer en si morir / y no confesar lo que no hiço mas medio ano y un año, doa años, tres años, quatro / años y veces ocho años, no creo que es nasçido hombre humano por valeroso o que sea I que si no es por gracia de Dios sostenido y alguno ay no es hombre sino martir / del cielo mira buen Rey, por rreverencia de Dios, mira, mira mira bien / en esto y sentirlo que ynfinito mas passa de lo que digo ynformaos de lo que os / movera a mucha piedad... es que sacaron al auto cinquenta o sesenta persona unos con candelas en las / manos otros con mordaças y otros con coraçcas, y otros con sanbenitos y publican / en toda España y aun en toda la christiandad que hubo un auto en Toledo / Debienen erejes y pudo ser que no obodos ni uno que se pudo decir verdadera / mente erejemira Señor que es crueldad mira Señor ques mengua de Hespaña /... ${ }^{14}$.

Le parece inconcebible el tipo de trato que reciben los inculpados, incluso cuando se les ha encontrado inocentes:

«... o buen Rey Remedio, o buen Rey Remedio, / o buen Rey Remedio, o buen Rey Remedio, por rreverencia de christo que / despues de averiguado

13 Fol, 14v.

14 Fols. 14v-15r. 
y bencido un hombre como en otros juicios gravissimos / se hace las mas crueles penas del mundo son livianas para lo que mercen / mas antes que averiguen serlo porque se anden quitar las defensas nadie porque / los privan luego de los sacramentos y de la participacionde los fieles, porque / los tratan luego peor que condenados con que les saitsfaran a los que padecen / y passan por estos y sufren tantas ygnomias, y la ynfamia / de ser presos por la santa ynquisicion saliendo libres porqeu de que salen libres / no los pregonan por buenos, y les dan otros tantos dulces tragos quantos / amargos les han hecho venir, porque no les satisfacen todas las perdidas que le an / sucedido por su pission, no se por cierto que por merced de dios les hace al ques presso / aun que salga libre sale desonrrado y ynfamado y perdido y por libre que salga / dexa un buen rrepellon para el gasto del sancto officio no digo justo ny ynjusto / sino que dios es savedor de todas las cossas y no tengo de habla enperjuicio / de nadie ni celo es tornar por el braço caydo quepadecen y no osan / hablar y esperan el dia del remedio yen esto se deve demostrar la / grandeza de los Principes" ${ }^{15}$.

Describe el odio que sienten los «labradores» hacia los «conversos», del miedo que todos tienen a verse acusados injustamente, y el autor nos describe su «propio miedo» ante el texto que está redactado, pues puede costarle la vida:

«Buen Rey si los inquisidores fuesen un San Francisco, un San Genaro / mismo San Agustin y los testigos los santos martires / y los secretarios fuessen los sanctos confessores desde el tiempo que pren / dieran algunos por la sancta Inquisicion fuera justo ... mas mira Señor / que los inquisidores son honbres y los secretarios son honbres / tan pecadores como otros y aun muchos dellos labradores nacion muy / contraria de los conversos que havido inquisidor dellos que decia damelo / confesso y dartelo quemado, y otros que an venido por opinion que nin/ gun confesso puede ser bue christiano y otras mill quentos de cossas que / aunque las gentes lo savien las pudren en su coraçon por temor, por / de quien padece, que estos que escrivo con el celo que Vuestra Majestad puede ver / y sin prejuiciode persona alguna del sancto oficio estoy temblando / no se me asgan alguna palabrilla para que me metan a donde / nunca salga si la sonbra de tus alas no me defende que aunque yo / hago siento no pienso sino quel papel y tinta y pendola con que escrivo / me a de descubrirmira señor que los testigos son honbres y onbres que / por la mayor parte son testigos para dañar a otros, unos honbres desalma / dos que no temen a dios ni al mundo y ay destos quinientos mill que haran / los juramnetos falsos..." ${ }^{16}$.

En el Memorial, el autor nos describe el temor que se extendió en su época a todos los niveles de la vida hispana, provocando que ninguna

15 Fol. 16.

16 El profesor Avilés nos habla de que por primera vez la teoría de Américo Castro queda aquí corroborada, cuando decía en sus trabajos que en realidad no era toda España la que odiaba a los conversos sino sólo los «labradores». AviLÉS Fennández, M., Motivos de crítica, pp. 185-186 (Castro, Américo, La realidad histórica de España, México, 1982, p. 48). 
persona se atreviera a decir lo que pensaba o sentía, por miedo a ver trasgiversadas sus ideas:

«Mirad señor que los predicadores no ossan predicar y ya que predican / no ossan meter en cossas sotiles porque en la boca de dos necios / esta su vida y honra y no ay nadie sin su alguaçil en esta vida que ay / doctores ynabilitados en nuestra España que bastarian para confundir a lutero / y sean ydo a rreynos estraños a mostrar su grandeca de letras y en España / no osan hablar y los padres no osan que aprendan los hijos sancta theolo / gia por este temor y sin falta vendra España en mucha diminucion / de letras en esta ciencia por que no osan hablar ni aun gran disputando. / Mira señor que en otras nasciones ay honbres riquisimos que bastan / para socorrer a Vuestra Majestad en tiempo de necesidad y con Vuestra Majestad / se enriqueçen pues hombres mas abiles ay en España sino que ninguno / llega a gallinero que los cortan en agras, que muy pocos se escapan / tarde o temprano de la sancta Inqusicion... ${ }^{17}$.

Intenta explicar el por qué se han instalado algunas familias ricas en tierras lejanas:

«Mirad buen Rey que poco a poco se desnaturalizan mucha gente rica / y sevan arreynos por no vivir toda du vida en temor y sobre / salto quando entrara un alguacil de la Inquisicion por las puertas / que mayor muerte es el temor continuo que la muerte presta penssa buen / Rey en esto y mete la mano en Vuestro pecho que honbre sois que mientras / mundo fuere mundo si Vuestra Magestad no la rreforma no faltaran en el Sancto / officio culpados, como o de que manera justa, o ynjustamente diose / el savidor y Vuestra Magestad solo lo podria escodriñar como Rey Catholico / y Justiciero por que yo no he de hablar en perjuicio del oficio ni ministros / del porque temo alguna descomunion que me llegue mas / para el havito de San Pedro que si las cossas que yo se en cofession..." ${ }^{18}$.

A continuación, el autor pasa a describir el tipo de medidas que debe tomar el emperador, para intentar resolver la terrible situación en que la Inquisición ha hecho caer a España, sobre todo señala nuestro relator el interés económico que tienen los inquisidores en encontrar culpables:

"Lo que Vuestra Magestad de dios deve proveer ante todas / cossas que el gasto del sancto oficio no sea de las haciendad de los conde / nados porque rrecia cossa es que sino queman no comen, sino conde / nan moriran de hambre, y quien muere de hambre ...seria bien que de las / rentas de la iglesia seden salarios alos oficiales pues es honra / de Dios y esta mexor que en la justicia seglar / ...

\footnotetext{
17 Fol. 16r.

18 Fols. $16 r-16 v$.
} 
Provee buen Rey que losinquisidores sean hombres ydalgos y no sean / labaradores porque cossa rrecia es que labradores sean jueces de conversos / porque son ynimicissimis y en los hombres hidalgos aay toda limpieça / e bondad /.

Prove Buen rrey que el que bien haçer alguna eregia la vaya a de / poner dentro de un buen termino so gracia que a quel passado / no sea oydo, y sea el castigado gravemente por en ello encubreno / porqeu acaesçe de lo que bieron agora treinta e quarenta / ççinquenta años ua quellos tales de creer es que bienen cn malicia/ que son mas ereges que no aquellos de quien ponen pues tanto tiempo / lo an rretenido en ssupecho biendo que es onrra de dios yquesta descomul / gado en nodecillo./

Provee Buen Rey un termino convenible dentro del qual sean obli / gados los inquisidores a hacer cargo a los culpados y otro breve termino para / que se desermine su causa y otro breve termino para que las caussas / conclusas se sentençien por que no se martiricen los onbres largas / prisiones y que no se desesperen como emos visto a muchos y por que / no les desfallezcan el animo y destruyan assi en su linaxe, sino que / como fueren prendiendo vayan sentenciando y executando porque / de que sirve aquellos autos ponpossos sino para desonrrar a España / y destruir gentes noe es piedad christiana por cierto./

Prevee Buen Rey que como en todos los delitos del mundo / aunque conspiren su sacra magestad ay carceres abiertas / para que les puedan hablar e consolar que assi sea en el Sancto officio / que mas piadosso es Jesucristo para perdonar lo que toca a su onra / que los rreyes temporales ...que / por dios que me parece que si la pesquissa que contra los conversos anda / andubiesse contra los sanctos del cielo que allasen muchos que pudiesen / condenar por erexes no por que lo que siendo sanctos no podian ser / herexes sino por falsos y malos que ay en el mundo y por la sseguridad $\tan /$ grande de que en este oficio seussa y por los jueces que no dexan punto / de rigor...

Preovee Buen Rey que por el delito de los Padres no se ynaviliten los / descendientes que cossa gravissima es que por el delito del que bive se castigue / el que esta por nacer y que antes que una cristura sea engendrada / en el bientre de su madre sa ynnaculada de todo ofico y beneficio / que menos pena seria privarlos de la vida quando no sienten que quita / rlos la onra quando entienden que vien paresce ynventado en / tiempo de gentilidad que lso emperadores lo inventaron en a que / tiempo por su propio ynteresse por que no los matasen, Nuestra fee es ley / de graçia que no de rrigor./

Prevee buen Rey que a los hijos les quede algo con que sustenten / poque es crueldad privarlos de iodo punto y que dexen rreposar/los muertos que supago tienen de lo que obraron si malos fueron / y despues demuertos como se podran defender./

Provee buen Rey que aya publicacion de testigos porque donde que adan se formó en todas las leyes del mundo nunca çesso / de haçer porque en Juicios livianos y de poca calidad cada dia los / testigos ... de falsos pues en este sancto oficio a donde / tanto ba que es fama y bida, y honra y hacienda de todo un linaxe / y aun a las bueltas las almas porque sea de dexar de dar 
antes les a / vian de amidir defenssas que no quitarselas aba Señor que se juzga / que se açe enbengança de lo que los judios hicieron a Jesuchristo quando / le abofeteaban y dcian profetica quien se dio y esto seria sentir mal / de nuestra santa fee porque es de ley de piedad y missericordia y de gracia y no / de bengança, y en la cruz los perdono y rrogo al padre por ellos y es / muy granburla decir que si publicacion de testigos se haçe no ossaron / los testigos deponer porque vemos que por temor de las excomuniones / que los ynquisidores echan sacando la cruz con luto y bistiendose / de silicio y amatando candelas. Los Padres han llorando a deponer de los hijos y los hijos de los padres, y los hermanos de los hermanos / y las mugeres de los maridos y los maridos de las mugeres siendo / una misma carne y no osan menos hacer, llorando de ponen / lo querrian antes cortan la caveça que decirlo. Porque sea de / creer que ningun christiano querra vivir y morir descomulgado por no /decir lo que vido y save, no es credero por cierto. hace buen Rey una cossa manda que cada año en cada pueblo se quemen dos / otres estatuas en nombre de aquellos que saven alguna eregia y no / la descubre por miedo, amor, o temor, o pone otras graves penas / que ninguno sera tan mal mirado christiano que quiera bersse / quemar en bida por encubrir por temor las eregias ...Señor que en cada pueblo se pregone amparo es seguro / Real a todos los que fueron a deponer al oficio, Prevee mas Señor emprendiendo a alguno los inquisidores hagan paresce antesí / todos sus deudos asta la quarta generacion y todos se publiquen / por la yndemnidad y menoscavo de los testigos antes que se haga la / publicacion y desta manera estaran mas seguro que agora estan que aun agor ay aparexo de tomar bengança de algunos porque / por secreto que se tomen se trasluce quien en algunos y de aquellos se puede tomar bengança ...Buen Rey Piadosso / y Justiciero debe hacer atento a la onra de España, y a la mexoria de / sus obras y costumbres que por la gracia de Dios en ellos a obrado el espiritu / santo, y a lo mucho que V.M., le deve en amor, y al servcio leal / que a V.M. siempre hicieron y postrero final a lo que V.M. deve / a buen christiano y Rey Catholico para la buena governacion de sus / Reynos y de cargo de su conciencia ayuda al braço caydo porque / Jesuchristo os ayude contra el turco ynfiel...

Buen Rey ofrecesseme al entendimiento tantas caussas paarentoria $\mathrm{Pa}$ / ra que V.M. deva de pura obligacion rreformar e moderar el rrigor del / Sancto oficio ...prevee Señor, como sea Santo oficio y no vengança de enemigos / castigo de culpados, y no martirio de ynocentes prision de los malos y no poço parra los buenos, ordena señor que alos testigos que se averiguare / ser enemigos de aquellos de quien deponen que les sean cortadas las len / guas y a los que provaren ser falsos les sea dala la lema del talion / No se como dexe de deçir que padeçe que se juega con las bidas y fonrras / de los hombres ... los que poco pueden los que mueren biviendo los que no tienen / osadia ni atrevimiento de descubrir sus coraçones los que viven en perpetuo / temor sin causa pordotenello dicen que pues dios Nuestor Señor los quiso tanto / que todo lo que el mas valerossisimo principe del mundo reservo en si en señal / de la suprema potestad que despues de dios en el mundo tiene, despues de / rreservando en su pecho en tal manera. Prevee lo que es servido que biene / todo organiçado por el catholico consejo de V.A. que aya por bien / deleer y entender y sentir 
esta carta que a su magestad escriven lo que poco / pueden y proveer y rreformar en ella como balga verdad a las gentes / y como con color santo no sean martiricados los ynoçentes y como por / alcançar un ereje no sean tropellados treinta christianos y plu / guiasse a dios que se pudiese decir tropellan y no condenan / y como la onrra del christiano sea apocada pues por la gracia de Dios / ya agora se puede intitular christianissima no pueden los que poco pueden / que se quite la sancta ynquisiçion que no serian christianos si tal pidiesen / sino que se aclare y rreforme de tal manera que no se quiten a los / honbres las defenssas para que se pueda manifestar su linpieca y que / entre tanto que se averigua si son herejes o no los traten como christianos / y no como herejes quitandoles la participacion de los Sacramentos / y de los fieles y otros mill quentos de ynominias que se ace a sus personas / que en perjuicio muy grande de su onrra y vida y hacienda y de todo / su linaje que en la forma de averiguar si son herejes o no que pues / tanto ba en ello que sean juzgados por leyes justas ordinarias, y no por consti / tuciones desaforadas que quando los rreyes catolicos las ordenaro fueron / muy necessarias por la cofussion de las leys y agora muy dañosas por / las malicias y rrancores e ynpetus abominables y poca conçiençia que ay en / las gentes que se provea de forma que se pueda deçir Santa Inquisicion / y no poco ayron y se pueda deçir martirio de culpados y no castigo de ynocen /tes..." ${ }^{19}$.

\section{A MODO DE CONCLUSIÓN}

El autor del Memorial emplea la lengua "romance» para explicar a Carlos I de España el cómo y el por qué decide redactar este texto, en el que «le va la vida».

Utiliza un vocabulario sencillo y un estilo reiterativo, como si en ocasiones no recordara lo que había escrito con anterioridad. Tenemos la sensación que no trabajó en el texto de forma continua, y que pasó un lapsus de tiempo importante entre la primera parte (hasta el fol $15 \mathrm{r}$ ) y la segunda. La ortografía no es uniforme («hereje», "erege», «ereje», «ace», "açe», «hace», «onra», «onrra», «honra», etc.). También hemos notado una tendencia del autor a entrelazar diferentes palabras (hemos llegado a contar hasta seis) como si fueran una sola.

La idea central y objetivo del anónimo es llamar la atención del monarca sobre el comportamiento de los inquisidores y del Santo Oficio, repitiendo sin cesar que no pretende la anulación de la Inquisición, sino su reforma.

19 Fols. $17 r-19 \mathrm{v}$ 
Evolución y crítica de un problema social. Conversos y oposición inquisitorial...

Hemos podido observar que el texto consta de dos partes bien diferenciadas: en la primera de ellas se explica por qué la Inquisición debe adaptarse a los nuevos tiempos, para terminar, en la segunda, con una serie de soluciones necesarias al cambio.

\section{Primera parte: Causas de la necesidad de un reforma}

1. Hace referencia a la noción de «justicia»: la necesidad de una reforma del sistema inquisitorial, para que este sea más justo, «para gloria de Dios".

2. Nos explica por qué él personalmente se decide a redactar este texto ante el silencio de la sociedad hispana de su tiempo:opina que el emperador, al encontrarse tan ocupado en sus campañas militares no se da cuenta de lo que realmente está ocurriendo en la sociedad española; los «caballeros», por seguirle, se encuentran también muy ocupados;a los "prelados», quienes podían haber alzado la voz y prevenirle, no están interesados por la suerte que corran sus feligreses; los «hidalgos» están asustados ante la posibilidad de ver analizado su pasado y el de sus familias; los «conversos» tienen miedo de ser encarcelados por los inquisidores; y por último los «labradores» por el odio a los conversos, a los que desean ver caer en manos del Santo Oficio. $Y$ añade que si no pone remedio, muchos inocentes morirán.

3. El autor piensa que cuando se estableció la Inquisición, en el periodo de los Reyes Católicos, la sociedad hispana estaba muy «mezclada» y la «herejía de los malos cristianos» se hallaba muy difundida. Pero pone en entredicho su existencia, tal y como funciona a principios del siglos XVI, tras la expulsión de judíos y musulmanes, y la quema de sus libros. Añade, que de vivir aun Isabel y Fernando estos ya la hubieran remodelado y adaptado el Santo Oficio a los nuevos tiempos.

4. Aduce que alguno de los delitos por los cuales se ven llevados ante los inquisidores algunos inculpados podrían ser solventados por jueces y tribunales ordinarios, sin necesidad de pasar por la Inquisición.

5. Habla de las injusticias del sistema inquisitorial:el aislamiento total de los detenidos en las cárceles, confiscación de bienes, el no poder recibir sacramentos, etc, durante años, que tiene como única meta la de realizar fastuosos autos de fe. El autor nos dice que este trato es inhumano, y que al final los detenidos confiesan, sólo para terminar con su agonía, pecados que en su gran mayoría no han cometido. 
6. Añade que incluso en el caso de ser considerados «inocentes», no se da publicidad a la sentencia, y han perdido años en prisión, al igual que honra y fortuna, el inculpado y toda su familia.

7. Comenta que la gran mayoría de los inquisidores son «labradores» y estos odian a los conversos, y de ahí el trato injusto que dan a los acusados, que en su mayoría pertenecen a este grupo social.

8. El control inquisitorial es tan grande a todos los niveles de la vida española, que nadie osa decir lo que piensa, pues los que «hablan» antes o después saben que van a caer en manos de los inquisidores. Esta es la causa de que muchas familias con recursos se intalaran fuera de las fronteras, donde no se sentían oprimidas ante el yugo del Santo oficio.

Segunda parte: las soluciones

El autor opina que deben ser puestas en funcionamiento lo más rápidamente posible las siguientes medidas:

a) Preveer de salarios a los inquisidores, para que estos no estén obligados a condenar sistemáticamente "para poder comer».

b) Los inquisidores deben ser «hidalgos», y no «labradores», ya que estos últimos odian a los conversos.

c) Límite de tiempo para juzgar a los inculpados.

d) Cárceles abiertas, donde se pueda visitar a los ajusticiados.

e) Que los delitos de los padres no pesen sobre los hijos.

f) Que no sean confiscados todos los bienes de los inculpados, para que su familia pueda continuar viviendo normalmente.

g) Publicación de testigos.

h) Que la Inqusición no sea «venganza de enemigos»;que si se descubren falsos testigos se les corte la lengua como castigo.

i) Que no se prohiba la participación de los inculpados en los sacramentos.

Al terminar estas páginas nos seguimos preguntamos si el autor del Memorial tue «clérigo», «hidalgo» o tal vez «converso». Lo que si podemos decir, que aunque con miedo, se atreve a tomar la palabra ante la posibilidad de que nuevos inocentes caigan en manos de la Inquisición. Nos parece que a pesar del temor, del dolor, de la tristeza, de la dificultad de 
Evolución y crítica de un problema social. Conversos y oposición inquisitorial...

su situación personal, dividido entre su miedo y su deber moral, que no le permite continuar callado frente a lo que está presenciando, él toma una decisión que le puede llevar a la muerte. Afortunadamente para el género humano, siempre hay gente que, a pesar de todo, su conciencia no les permite restar impasibles ante aquello que consideran una injusticia y una afrenta a la sociedad. 